\title{
Does the EU emissions trading system help reduce PM2.5 damage? A research based on PSM- DID method
}

Liang Wan ( $\square$ wanl001@ustc.edu.cn )

University of Science and Technology of China https://orcid.org/0000-0003-3167-6591

\section{Shanyong Wang}

University of Science and Technology of China

Jianing Zang

University of Science and Technology of China

Qiaoqiao Zheng

University of Science and Technology of China

Wenpei Fang

University of Science and Technology of China

\section{Research Article}

Keywords: EU ETS, PM2.5 emission reduction, PSM, DID method, Synergistic governance effect

Posted Date: April 23rd, 2021

DOl: https://doi.org/10.21203/rs.3.rs-385814/v1

License: (9) This work is licensed under a Creative Commons Attribution 4.0 International License.

Read Full License

Version of Record: A version of this preprint was published at Environmental Science and Pollution Research on November 20th, 2021. See the published version at https://doi.org/10.1007/s11356-02117640-x. 


\section{Abstract}

Air quality, especially haze pollution, has become an important issue that threatens the sustainable development and health of human beings. To study and formulate effective environmental regulations to control and reduce the concentration of $\mathrm{PM}_{2.5}$ in the air, especially to clarify the effect of the relevant emission trading system on the emission reduction of air pollutants is a research topic with important practical significance and theoretical value. Previous studies on the environmental effects of emissions trading system (ETS) generally focused on carbon emission and their intensity, instead of focusing on the synergistic governance effects between ETS and PM ${ }_{2.5}$. Based on the PSM-DID method, this paper selects $\mathrm{PM}_{2.5}$ damage and other related data from 147 countries in the World Development Index (WDI) database. This paper examined whether the EU ETS has a spillover effect on $\mathrm{PM}_{2.5}$ damage reduction, and further discussed the related impact mechanisms and approaches. The research results show that the EU ETS has promoted the reduction of $\mathrm{PM}_{2.5}$ damage, and at different stages of implementation, the impact of the EU ETS on the reduction of $\mathrm{PM}_{2.5}$ damage has a dynamic effect. After discussion, it is found that ETS mainly affects $\mathrm{PM}_{2.5}$ emission reduction through two channels: pollution industry transfer, industrial structure upgrading and green technology innovation. Finally, this paper gives relevant policy suggestions, which can encourage companies to achieve carbon emission reduction targets while helping to reduce $\mathrm{PM}_{2.5}$ emissions, and eventually achieve a win-win situation between economic growth and environmental improvement.

\section{Introduction}

Air pollution has become an important issue that threatens the sustainable development and health of human beings. As an important component of air pollutants, PM2.5 is the culprit. PM2.5 is also the main air pollutant that causes haze (Dong et al., 2019a). A research report in the "Environmental Research Bulletin, 2013" shows that the number of deaths caused by air pollution in the world is about 2.1 million each year. The main cause of death is the increase in the concentration of suspended particulate matter such as PM2.5 in the atmosphere, which causes damage to the human lungs. The "Global Environment Outlook 5" (2012) pointed out that nearly 2 million premature deaths were related to particulate pollution. The report from the European Union Environment Agency (2016) also pointed out that about $85 \%$ of Europeans are exposed to the harmful environment of PM2.5 particles recognized by the World Health Organization. Although these fine particles cannot be seen or smelled, they do have devastating effects on the human body, including causing or aggravating heart disease, asthma and lung cancer (Xu et al., 2019). Therefore, to study and formulate effective environmental regulations to control and reduce the concentration of $\mathrm{PM}_{2.5}$ in the air, especially to clarify the effect of the relevant emission trading system on the emission reduction of air pollutants is a research topic with important practical significance and theoretical value.

A reasonable ETS program can not only promote the progress of energy saving and emission reduction, but also an important starting point for collaborative environmental management (such as air pollution) 
(Yan et al., 2020), it can effectively control air pollution and climate change, and accelerate the effectiveness of environmental and ecological governance (Zhang, 2015; Li et al., 2019). As it is well known, greenhouse gas and air pollutant arise from the same source, both are mainly caused by the combustion of coal, oil, and natural gas. Therefore, the actions to reduce $\mathrm{CO} 2$ and PM2.5 emissions are consistent, and the realization of coordinated control of air pollutants and greenhouse gas emissions also has a realistic basis (Xian et al. al., 2018). In the process of reducing greenhouse gas emissions, the emission of atmospheric pollutants PM2.5 can be effectively controlled. The resulting environmental health benefits will offset the emission reduction costs and improve the cost efficiency of the implementation of ETS (Yang et al ., 2013). Therefore, the establishment of an effective ETS can not only reduce carbon emissions, but also coordinately curb air pollution and improve air quality. Based on this, study the impact of the ETS on PM2.5 emission, especially to clarify the differences of the impact in the three stages of the implementation of the EU ETS, will be an effective supplementary study on the effectiveness of collaborative governance of the current EU ETS, and will also enrich the research content and scope of the current ETS.

With the implementation of ETS, its impact has aroused widespread concern in previous studies. Preliminary research mainly focused on the environmental effects of ETS, such as researches on the role of ETS in carbon emission reduction (Laing et al., 2014; Muûls et al., 2016; Li et al., 2019). In addition, scholars continue to study the spillover effects of ETS, such as changes in corporate profits (Smale et al., 2006), energy prices (Kara et al., 2008), industrial investment (Laing et al. , 2014) and low-carbon consumption et al. There are also researches that focus on studying the role of ETS in industrial structure adjustment, such as Zang (2020) based on the PSM-DID method, using EU carbon emission data from 2000 to 2018 to investigate whether the implementation of ETS has spillover effects on the industrial structure upgrade. However, as PM2.5 governance is an important part of environmental regulation, few scholars have studied it from the perspective of environmental regulation theory (Lv et al., 2015; Liu et al., 2020). By combing through the literature on PM2.5, we found that research on PM2.5 at this stage most focuses on the analysis of the composition of PM2.5, source, hazards, pathogenic mechanism and other issues. The literature that directly studies the effect of ETS on PM2.5 emission reduction is even rarer. Only a few scholars such as Yan et al. (2020) have tested the cooperative control effect of the ETS on air pollution based on the ETS pilot with Chinese characteristics. In view of the shorter implementation time of the Chinese ETS compared to the EU ETS, its implementation stage is still in the first stage, and the Chinese ETS has not yet established a nationally unified trading system, which is far behind the EU ETS in terms of content, coverage and maturity. Therefore, this study takes the EU EST as the core research subject, in order to obtain more convincing research results, and we believe it will provide more valuable suggestions for the subsequent system design, implementation and improvement of other related ETS.

In summary, in order to fill the above research gaps, this paper selected PM2.5 damage and other related data from 147 countries in the World Development Index (WDI) database, based on the PSM-DID method, we examined whether there is a spillover effect of EU ETS on PM2. 5 damage reduction. The main contributions of this paper are as follows: 1 . In terms of research background, this is the first empirical study on the effect of the EU ETS pilot on the coordinated control of air pollution, as the previous studies 
mostly focused on the carbon emission reduction and environmental effects of ETS; 2 . In terms of research scope and data collection, most of the research on emissions trading is limited to the provincial or industry level, and most of the PM2.5 data uses concentration data and lacks total emissions data. This paper has obtained actual PM2.5 damage data from 147 countries, which is helpful to fully evaluate and compare the different situations of pilot countries and non-pilot countries before and after the implementation of the policy; 3 . In terms of research methods, this paper accurately evaluates the "net effect" before and after the implementation of ETS by constructing a PSM-DID model. In particular, we have clarified the effect of EU ETS on the reduction of PM2.5 damage in the pilot countries, and the changes in its impact at different implementation stages.

\section{Literature Review}

Together with practical advance of ETS, its direct or indirect outcomes continued to be studied. Prior studies on the outcomes of ETS mainly followed four cues. The first cue is regard to its direct effects on emission reductions (e.g., Laing et al., 2014; Muûls et al., 2016; Li \& Jia, 2016). The second cue focused on the contingent effect of ETS on economic indicators (Wang, 2012; Hoffmann, 2007; Abrell et al., 2011; Anger and Oberndorfer, 2008; Zhang and Wei, 2010). The third cue investigated the positive effects on carbon productivity (Cui et al., 2014; Zhang et al., 2017). Finally, the fourth cue investigated the potential impacts of ETS on technology innovation (Porter, 1996; Porter and Linde, 1995; Van and Mohnen, 2017; Cerin, 2006). However, as PM2.5 governance is an important part of environmental regulation, few scholars have studied it from the perspective of environmental regulation theory, especially the related research on the relationship between EU ETS and PM2.5 emission reduction, and the research on its influence mechanism are even rarer (Lv et al., 2015; Liu et al., 2020).

Through combing the current research on PM2.5, we found that current researches mainly focus on the influencing factors, composition, harm and pathogenic mechanism of PM2.5, the formation of PM2.5 mainly affected by meteorological conditions and human activities. Research such as Shao et al. (2016) found that although the frequent occurrence of haze pollution is affected by climatic factors to some extent, the extensive economic development mode, unbalanced industrial structure, low energy efficiency and low environmental governance efficiency is, the the ultimate influencing factors. Therefore, from the perspective of socio-economic influencing factors to analyze the causes of haze has gradually become the mainstream direction. Based on the STIRPAT model, Xu and Lin (2016) found that these factors such as economic development, urbanization, private car ownership, coal consumption and energy efficiency have significant differences in the impact of PM2.5 emissions in different regions. Some scholars also study on PM2.5 emission reduction from the perspective of policy tools, common policy tools include resource tax (Sancho, 2010), sulfur tax (Xu \& Masui, 2009), carbon tax (Allan et al., 2014). While, due to the lack of specific PM2.5 emission data, the current research is mainly based on PM2.5 concentration data (Dong et al., 2019b). This leads to the inability to effectively analyze the specific emission reduction path and impact mechanism of PM2.5, especially the inability to accurately assess its dynamic changes with the implementation of the policy over time. Which is also an obvious shortcoming of current research. 
At the same time, a large number of studies have confirmed the synergistic effect of greenhouse gas emission reduction on air pollution mitigation. Xue et al. (2015) quantitatively evaluated the synergistic benefits of wind power generation based on the life cycle analysis method. Vennemo (2009) et al. compared the benefits and costs of three different $\mathrm{CO} 2$ emission strategies (including intensity, total emission, and industry intensity), and concluded that intensity control has the greatest environmental synergy. In addition, a number of studies have confirmed that greenhouse gas reduction strategies will improve air pollution and bring public health benefits (Haines et al., 2009; Nemet et al., 2010 Groosman et al., 2011;). However, the existing studies on the synergistic effects of air pollutants and greenhouse gas emissions mostly use complex models for simulation analysis, there are too many assumptions and constraints, and the results of quantitative analysis can only be regarded as predicted values or theoretical values, without detailed analysis of historical data. At the same time, previous studies on the environmental effects of ETS generally focused on carbon emission and its intensity, rather than focusing on the synergistic governance effects between ETS and PM2.5 (Li \& Zhang, 2017).

So far, the research on PM2.5 governance from the perspective of environmental regulation theory is still a gap that needs to be filled urgently, and it is rarely to find studies that use ETS as an explained variable. Preliminary studies such as Lv et al. (2015) analyzed the dilemma of PM2.5 governance in China based on the perspective of environmental regulation theory, and gave relevant policy recommendations, they pointed out that the problem of PM2.5 governance is manifested as weak environmental law enforcement. Zhang (2017) built a spatial interaction model of urban pollutant emissions, the study found that although the total amount of pollutant emissions in Chinese cities has been reduced, the concentration of PM2.5 in the air has not shown a significant decline. He further pointed out that the magnitude and scope of the impact of current environmental regulations need to be further strengthened, especially in key industries and related industries. Liu et al. (2020) studied the relationship between environmental regulations, spatial spillover effects and urban air pollution by constructing a spatial Dubin model, they identified the effectiveness of air pollution control in the city. It can be seen that the previous studies are mostly based on the perspective of general environmental regulation to study the effect of PM2.5 governance. Only a few scholars, such as the latest research by Yan et al. (2020), have studied the relationship between China's ETS and air pollution by constructing an empirical model for the first time. As mentioned above, the implementation time of Chinese ETS is shorter than that of EU ETS, and its content, coverage and maturity are far less than EU ETS. Moreover, the PM2.5 data used in the study by Yan et al. are speculative data, not actual emission data. Therefore, based on the historical data of PM2.5 damage in 147 countries of the World Bank, this paper constructs a regression model to quantitatively analyze the impact of ETS on PM2.5 emission reduction, we believe that more convincing evidence will be obtained.

\section{Research Design}

\subsection{Data collection}


This part of the analysis mainly involves objective data such as PM2.5 emission damage and related economic indicators in various countries, these data come from the World Development Indicators (WDI) database of the World Bank. The WDI database collects and compiles hundreds of indicator data related to global development, covering various countries and regions around the world, and the data source is authoritative and accurate. The economic development indicators of the countries (regions) involved in this part of the study include: Gross domestic product (GDP), per capita GDP, gross domestic income (GDI), consumer price index (CPI), the proportion of secondary and tertiary industry output in GDP, employment status, and airborne fine particulate matter (PM2.5) emissions index. Due to the availability of WDI data, the time span of panel data studied in this section is from 2000 to 2017. After excluding countries or regions with missing data, a total of 147 countries and regions are left.

\subsection{Research method}

This paper uses the difference-in-difference (DID) method based on propensity score matching (PSM) to study the spillover effects of ETS on environmental pollution damage. DID is a commonly used quasiexperimental method to estimate the causal effects of specific public policies (such as the ETS studied in this article) (Stuart et al., 2014). Since the implementation of a public policy is usually not affected by the subject, the implementation of the policy can be regarded as an exogenous "intervention" for the subject, therefore, the implementation of the policy can also be regarded as a quasi-experiment. The DID method is to estimate the net effect of policy implementation by comparing the result changes between the intervention group and the control group before and after the policy implementation. The principle is shown in Figure 1 below. Therefore, DID analysis can eliminate the estimation bias caused by timevarying factors (Stuart et. al, 2014). However, DID analysis also faces the endogenous problem caused by sample selection bias, that is, the samples in the control group are usually selected randomly. If the result trend or sample composition varies over time due to various confounding variables, it will lead to estimation bias.

The PSM-based DID method can solve the problem of sample selection bias caused by confounding factors (Caliendo and Kopeinig, 2008). PSM is a counterfactual causal inference method, it uses the common characteristics of a set of intervention groups and control groups, to match the intervention group to a similar control group sample as a new control group. This reduces the estimation bias caused by the confounding factor, and makes the comparison of the DID regression results of the intervention group and the new control group more reasonable. Therefore, the PSM-based DID method can effectively estimate the impact of specific policies on related results.

\subsection{Variable measurement}

\section{Dependent variable}

The dependent variable of this study is the damage caused by airborne fine particulate matter (PM2.5) emissions, which referred to as PM2.5 emission damage. Measured by the World Bank's statistical indicators for PM2.5 emission damage, that is, calculated according to the natural logarithm of PM2.5 
emission damage (priced in US dollars). The World Bank's specific description of PM2.5 emission damage is "Particulate emissions damage is the damage due to exposure of a country's population to ambient concentrations of particulates measuring less than 2.5 microns in diameter $\left(\mathrm{PM}_{2.5}\right)$, ambient ozone pollution, and indoor concentrations of $\mathrm{PM}_{2.5}$ in households cooking with solid fuels. Damages are calculated as foregone labor income due to premature death. Estimates of health impacts from the Global Burden of Disease Study 2016. Data for other years have been extrapolated from trends in mortality rates".

\section{Independent variable}

The independent variable of this study is the implementation of the ETS. Refer to the double difference analysis method, we construct two dummy variables and. Among them, indicates that the sample country or region belongs to the intervention group or control group. If the $i$-th country or region joins the ETS, then the country's is equal to 1 . On the contrary, if the country or region has not joined the ETS, the country's is equal to 0 . indicates the time dummy variable for the implementation of the ETS. If the ETS is implemented in year $t$, in the current year and subsequent years is equal to 1 , and in the previous year is equal to 0 . It should be pointed out that since the EU ETS was implemented step by step in three phases from 2005 to 2017, the specific content of implementation at each stage has gradually deepened, and a small number of non-EU countries have joined the EU ETS in each implementation stage. Therefore, for these countries that join in the later stage, their in the early stage is equal to 0 , and after joining, their is correspondingly equal to 1 . According to this, the independent variable of the double difference regression analysis is the cross product of and, namely *.

\section{Control variable/covariate}

With reference to previous research, this research controls for economic variables related to outcome variables (Apergis, 2016; Cheng, Li and Liu, 2017; Li and Lin, 2015; Yang et al., 2015). Firstly, the economic scale and degree of development of a country or region are often closely related to the emission of air pollutants, which will affect PM2.5 emissions. Therefore, we control the gross national product (GDP), per capita gross national product (per capita GDP), gross domestic income (GDI), and consumer price index (CPI) of each country or region. In order to reduce the dimensional influence, the natural logarithm of GDP, GDP per capita, and GDI is taken. Secondly, the industrial structure level of a country or region is also an important factor that affects the emission of fine air particles. Therefore, this paper controls the proportion of the output value of the secondary and tertiary industries in GDP and the employment situation (measured by the employment rate). Thirdly, it should be pointed out that, consistent with previous studies, this article also uses these control variables as covariates for the propensity score matching analysis when analyzing the sample countries.

The following table provides the symbols, definitions, and descriptive statistical analysis results corresponding to the above variables.

Table 1. Variable symbol definition and descriptive statistical analysis 


\begin{tabular}{|c|c|c|c|c|c|c|}
\hline Variable name & $\begin{array}{l}\text { Variable } \\
\text { symbol }\end{array}$ & $\begin{array}{l}\text { Number of } \\
\text { samples }\end{array}$ & Mean & Maximum & Minimum & $\begin{array}{l}\text { Standard } \\
\text { deviation }\end{array}$ \\
\hline GDP & InGDP & 2623 & 24.49 & 30.60 & 19.13 & 2.15 \\
\hline GDP per capita & Inpergdp & 2623 & 8.36 & 11.69 & 4.73 & 1.61 \\
\hline GDI & InGDI & 2515 & 27.21 & 36.83 & 19.21 & 3.09 \\
\hline Employment & labour & 2646 & 0.92 & 0.99 & 0.63 & 0.059 \\
\hline $\begin{array}{l}\text { Proportion of } \\
\text { secondary industry }\end{array}$ & service & 2394 & 0.53 & 0.96 & 0.05 & 0.13 \\
\hline $\begin{array}{l}\text { Proportion of tertiary } \\
\text { industry }\end{array}$ & industry & 2554 & 0.29 & 0.83 & 0.02 & 0.15 \\
\hline $\mathrm{CPI}$ & $\mathrm{CPI}$ & 2421 & 0.976 & 27.40 & 0.07 & 0.63 \\
\hline $\begin{array}{l}\text { PM2.5 emission } \\
\text { damage }\end{array}$ & InEMD & 2536 & 18.69 & 24.27 & 14.10 & 1.72 \\
\hline
\end{tabular}

\subsection{Regression model}

The EU ETS is actually implemented step by step in three phases: The first phase is from 2005 to 2007, during which a total of $25 \mathrm{EU}$ countries joined, mainly implement carbon emissions trading for power production and energy-intensive industries in these countries. At the same time, all carbon emission allowances are issued for free; The second phase is from 2008 to 2012. During this phase, Iceland, Liechtenstein and Norway joined, and related emission requirements were further strengthened, for example, nitrous oxide emissions are included in the emission reduction target, and the fines for violating emission regulations have also increased from 40 euros/ton to 100 euros/ton; The third stage is from 2013 to 2020. Based on the previous implementation experience, the emissions trading system has been adjusted significantly in this stage. The single emission cap within the EU replaces the previous independent cap system of participating countries, and at the same time, it covers a wider range of emissions. For example, include $\mathrm{CO} 2$ emissions from the aviation industry and perfluorocarbons (PFCs) from the aluminum production industry into the emissions trading system. It can be seen that different implementation stages may have significantly different consequences. Therefore, it is necessary to study the environmental governance effects of the EU ETS on PM2.5 emissions damage according to the specific conditions of each stage.

Refer to the research of Zang et al. (2020), regarding the environmental governance effects before and after the implementation of the EU ETS at each stage (ie. PM2.5 emission damage), this part uses double difference regression, and the regression model is as follows: see formula 1 in the supplemetary files.

In the above formula, represents the outcome variable, that is, the PM2.5 emission damage of each sample country or region before and after the implementation of the ETS, it is expressed as the natural logarithm of PM2.5 emission damage (priced in US dollars) and the proportion of PM2.5 emission 
damage to gross national income. As mentioned earlier, is a dummy variable that reflects the implementation of ETS. , respectively represent the individual fixed effect and time fixed effect of the country or region. is the control variable mentioned above, including the gross national product (GDP), per capita gross national product (per capita GDP), gross domestic income (GNI), consumer price index (CPI), the proportion of the output value of the second/tertiary industry in GDP, and the employment situation. represents the random interference items.

In addition, in the regression model of each stage, the time range of the sample panel data is the first five years of the intervention year of this stage to the year before the intervention year of the next stage (Due to the limitation of WDI data accessibility). Therefore, that is, the time range of the panel data of the first stage regression is 2000 to 2007, the time range of the panel data of the second stage regression is 2003 to 2012 , and the time range of the panel data of the third stage regression is 2008 to 2017 . At the same time, the intervention group and control group samples added to formula (1) are all samples after propensity score matching.

\section{Empirical Results And Discussion}

\subsection{Propensity score matching analysis results}

Since it is necessary to perform regression estimates on the governance effects of the EU ETS on PM2.5 emissions damages according to three different stages, and in the three stages, the countries of the intervention group also changed. Therefore, it is necessary to conduct propensity score matching analysis for the three stages to obtain the control group samples. $K$-nearest neighbor matching $(K=4)$ is used here, and the covariates of propensity score matching are as described in the previous section.

After propensity score matching analysis, the intervention group and control group countries or regions of the three phases of EU ETS implementation are shown in Table 2. Among them, in the first stage (the intervention year is 2005), after matching, there are 15 countries in the intervention group and 36 countries or regions in the control group. In the second stage (the intervention year is 2008), after matching, there are 18 countries in the intervention group and 20 countries or regions in the control group. In the third stage (the intervention year is 2013), after matching, there are 20 countries in the intervention group and 25 countries or regions in the control group.

Table 2. Intervention group and control group countries and regions obtained by matching propensity scores 


Group
Phase1
(Year of
intervention:
2005)

\begin{tabular}{|c|c|}
\hline $\begin{array}{l}\text { Intervention } \\
\text { group }\end{array}$ & 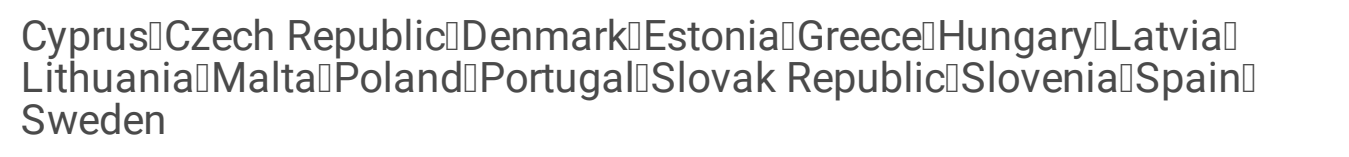 \\
\hline $\begin{array}{l}\text { Control } \\
\text { group }\end{array}$ & 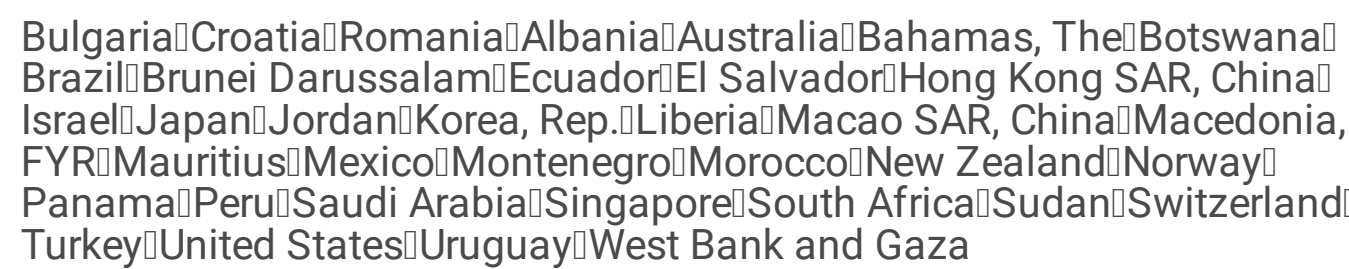 \\
\hline
\end{tabular}

Phase 2

(Year of

intervention:

2008)
Intervention Bulgaria $\square$ Cyprus $\square$ Czech Republic $\square$ Estonia $\square$ Germany $\square$ Greece $\llbracket$ Hungary $\square$

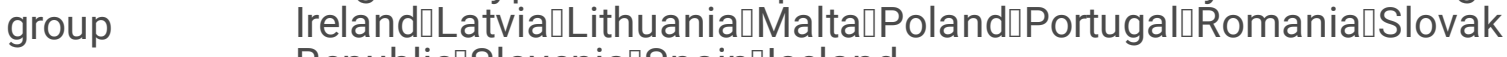 Republic $\square S l o v e n i a \square S p a i n \square l c e l a n d$

\begin{tabular}{|c|c|}
\hline $\begin{array}{l}\text { Control } \\
\text { group }\end{array}$ & 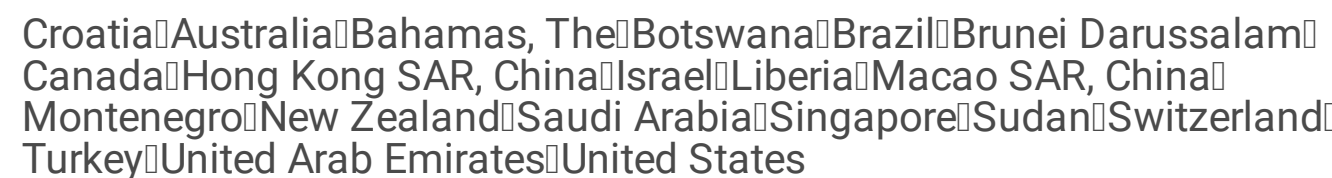 \\
\hline
\end{tabular}

\section{Phase 3}

(Year of intervention:

2013)

Intervention group

Control group
Bulgaria $\square$ Croatia $\square$ Cyprus $\square$ Czech Republic $₫$ Estonia $\square$ France $\llbracket$ Germany $\square$ Hungary $\square$ Ireland $\square$ Italy $\square$ Latvia $\square$ Lithuania $\square$ Malta $\square$ Poland $\square$ Portugal $\square$ Romania $\square$

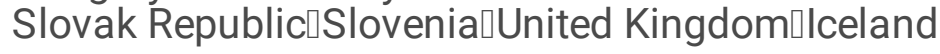

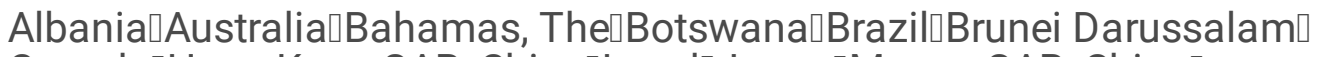

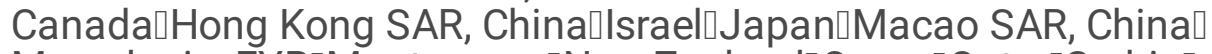

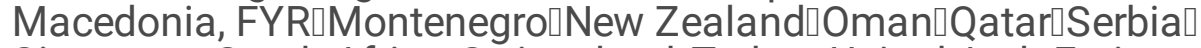
Singapore South Africa $\square$ Switzerland $\square$ Turkey $\square$ United Arab Emirates $\square$ United States $\square$ UruguayロVenezuela, RB

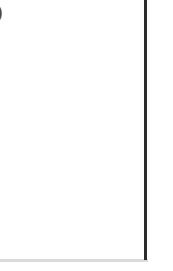


the balance test. Therefore, after matching, there is no significant difference between the intervention group and the control group in the three stages, which meets the requirements for further analysis.

Table 3. Balance test results of propensity score matching 


\begin{tabular}{|c|c|c|c|c|c|c|c|}
\hline Variable & $\begin{array}{l}\text { Un-matched } \\
\text { पUD } \\
\text { Matched } \mathrm{MM}\end{array}$ & $\begin{array}{l}\text { Mean } \\
\text { Experimental } \\
\text { group Control } \\
\text { group }\end{array}$ & Deviation & $\begin{array}{l}\text { Deviation } \\
\text { reduction } \\
\text { rate }\end{array}$ & $\mathrm{T}$ test & & \\
\hline \multicolumn{8}{|l|}{$t p>|t|$} \\
\hline \multicolumn{8}{|l|}{$\begin{array}{l}\text { Phase1 (Year } \\
\text { of } \\
\text { intervention: } \\
\text { 2005) }\end{array}$} \\
\hline InGDP & $U$ & 25.525 & 23.612 & 99.5 & 92.2 & 4.24 & 0.000 \\
\hline M & 24.707 & 24.856 & -7.8 & -0.18 & 0.855 & & \\
\hline Inpergdp & $U$ & 9.6890 & 7.4415 & 189.3 & 98.6 & 7.22 & 0.000 \\
\hline$M$ & 9.2624 & 9.2932 & -2.6 & -0.07 & 0.941 & & \\
\hline InGDI & $U$ & 26.269 & 27.327 & -37.6 & & -1.50 & 0.135 \\
\hline M & 25.887 & 26.120 & -8.3 & 78.0 & -0.20 & 0.842 & \\
\hline labour & $U$ & 0.9168 & 0.9076 & 16.1 & 97.1 & 0.64 & 0.524 \\
\hline M & 0.9046 & 0.9043 & 0.5 & 0.01 & 0.991 & & \\
\hline service & $U$ & 0.6123 & 0.5014 & 119.0 & 91.1 & 4.43 & 0.000 \\
\hline M & 0.5960 & 0.6058 & -10.5 & -0.23 & 0.816 & & \\
\hline industry & $U$ & 0.2528 & 0.2871 & -36.9 & & -1.36 & 0.176 \\
\hline M & 0.2582 & 0.2527 & 6.0 & 83.7 & 0.15 & 0.881 & \\
\hline $\mathrm{CPI}$ & $U$ & 0.8135 & 0.6466 & 130.2 & & 4.86 & 0.000 \\
\hline M & 0.7815 & 0.8082 & -20.8 & 84.0 & -0.66 & 0.518 & \\
\hline \multicolumn{8}{|l|}{$\begin{array}{l}\text { Phase2 (Year } \\
\text { of } \\
\text { intervention: } \\
\text { 2008) }\end{array}$} \\
\hline InGDP & $U$ & 25.768 & 23.976 & 94.0 & 73.6 & 4.19 & 0.000 \\
\hline M & 25.096 & 25.568 & -24.8 & -0.77 & 0.448 & & \\
\hline Inpergdp & $U$ & 10.023 & 7.8014 & 185.2 & 95.6 & 7.68 & 0.000 \\
\hline M & 9.5998 & 9.5032 & 8.1 & 0.27 & 0.791 & & \\
\hline InGDI & $U$ & 26.459 & 27.54 & -38.8 & & -1.64 & 0.103 \\
\hline M & 25.949 & 26.387 & -15.7 & 59.5 & -0.56 & 0.582 & \\
\hline
\end{tabular}




\begin{tabular}{|c|c|c|c|c|c|c|c|}
\hline labour & U & 0.9257 & 0.9139 & 23.3 & 70.8 & 0.94 & 0.347 \\
\hline$M$ & 0.9168 & 0.9134 & 6.8 & 0.22 & 0.826 & & \\
\hline service & $U$ & 0.6039 & 0.4985 & 101.4 & 98.6 & 4.10 & 0.000 \\
\hline$M$ & 0.5855 & 0.5840 & 1.4 & 0.04 & 0.971 & & \\
\hline industry & U & 0.2684 & 0.2959 & -23.9 & & -1.01 & 0.313 \\
\hline M & 0.2856 & 0.2729 & 11.0 & 53.7 & 0.30 & 0.769 & \\
\hline $\mathrm{CPI}$ & U & 0.8607 & 0.7510 & 112.2 & & 4.84 & 0.000 \\
\hline M & 0.8307 & 0.8137 & 17.3 & 84.5 & 0.50 & 0.619 & \\
\hline \multicolumn{8}{|c|}{$\begin{array}{l}\text { Phase3 (Year } \\
\text { of } \\
\text { intervention: } \\
\text { 2013) }\end{array}$} \\
\hline InGDP & U & 26.021 & 24.521 & 80.9 & 88.1 & 3.66 & 0.000 \\
\hline M & 25.682 & 25.504 & 9.6 & 0.27 & 0.789 & & \\
\hline Inpergdp & U & 10.266 & 8.2396 & 176.5 & 95.4 & 7.28 & 0.000 \\
\hline M & 9.9631 & 10.057 & -8.2 & -0.39 & 0.700 & & \\
\hline InGDI & U & 26.535 & 27.739 & -43.7 & & -1.88 & 0.063 \\
\hline M & 26.295 & 26.573 & -10.1 & 76.9 & -0.35 & 0.728 & \\
\hline labour & U & 0.9110 & 0.9231 & -23.9 & 74.8 & -1.02 & 0.311 \\
\hline M & 0.9065 & 0.9034 & 6.0 & 0.18 & 0.858 & & \\
\hline service & U & 0.6254 & 0.4971 & 112.5 & 94.1 & 4.64 & 0.000 \\
\hline M & 0.6135 & 0.6211 & -6.7 & -0.19 & 0.849 & & \\
\hline industry & $\mathrm{U}$ & 0.2509 & 0.3002 & -37.8 & & -1.59 & 0.114 \\
\hline M & 0.2637 & 0.2650 & -0.9 & 97.5 & -0.03 & 0.978 & \\
\hline $\mathrm{CPI}$ & U & 0.1009 & 0.1011 & -9.6 & & -0.38 & 0.707 \\
\hline M & 0.1010 & 0.1009 & 4.9 & 49.2 & 0.46 & 0.650 & \\
\hline
\end{tabular}

\subsection{Double difference regression analysis results}

Based on the sample of intervention group and control group obtained by propensity score matching, by using double differential regression, we analyzed the environmental governance effects of the EU ETS on PM2.5 emissions damage. This part first conducts an overall regression analysis of the effects of each 
stage, and then analyzes the dynamic effects of each stage. The specific empirical analysis results are as follows.

\subsubsection{Overall regression analysis: emission reduction effect of ETS on PM2.5}

The results of double difference regression based on propensity score matching are shown in Table 4 . Models 1, 2, and 3 respectively correspond to the first, second and third stages of the implementation of the EU ETS. The results of Model 1 show that through the implementation of the first phase of the trading system, the degree of damage to PM2.5 emissions in EU countries has increased compared to before the implementation $(,<0.01)$. The results of Model 2 show that the PM2.5 emission damages before and after the implementation of the second phase trading system are not significant. The results of Model 3 show that after the implementation of the EU ETS in the third phase, the PM2.5 emission damage of each member country has been significantly reduced $(,<0.01)$.

Table 4. Double difference regression results 


\begin{tabular}{|c|c|c|c|}
\hline & Phase 1 & Phase 2 & Phase 3 \\
\hline Model 1 & Model 2 & Model 3 & \\
\hline $0.08^{* *}$ & 0.007 & $-0.07 * \star$ & \\
\hline$(2.53)$ & $(0.24)$ & $(-2.24)$ & \\
\hline \multirow[t]{2}{*}{ InGDP } & $0.71 *$ & $0.88^{\star * \star}$ & 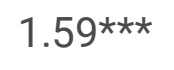 \\
\hline & $(1.81)$ & $(5.25)$ & $(5.04)$ \\
\hline \multirow[t]{2}{*}{ Inpergdp } & 0.19 & 0.08 & $-0.66^{\star \star}$ \\
\hline & $(0.48)$ & $(0.43)$ & $(-2.17)$ \\
\hline \multirow[t]{2}{*}{ InGDI } & 0.04 & -0.03 & 0.10 \\
\hline & $(0.32)$ & $(-0.30)$ & $(0.57)$ \\
\hline \multirow[t]{2}{*}{ labour } & 0.53 & -0.31 & 0.005 \\
\hline & $(1.00)$ & $(-1.19)$ & $(0.01)$ \\
\hline \multirow[t]{2}{*}{ service } & 1.05 & 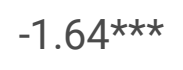 & -1.07 \\
\hline & $(1.60)$ & $(-3.56)$ & $(-1.29)$ \\
\hline \multirow[t]{2}{*}{ industry } & 0.05 & $-1.23^{\star \star \star}$ & -1.80 \\
\hline & $(0.07)$ & $(-3.70)$ & $(-1.45)$ \\
\hline \multirow[t]{2}{*}{$\mathrm{CPI}$} & $-0.55^{\star \star \star}$ & 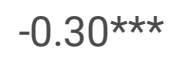 & 0.03 \\
\hline & $(-2.97)$ & $(-3.45)$ & $(1.05)$ \\
\hline$N$ & 371 & 352 & 395 \\
\hline 0.915 & 0.887 & 0.770 & \\
\hline
\end{tabular}

\subsubsection{Robustness analysis: the dynamic effects of ETS on PM2.5 emission reduction}

The dynamic effect analysis of double difference regression is to test the changes in the results of policy implementation over time, which helps to grasp the effect of policy implementation more clearly. Through the regression analysis of the dynamic effects of the three implementation stages of the EU ETS (see Table 5), after the implementation of the first phase of the EU ETS (Model 4), the emissions damage of PM2.5 from 2005 to 2007 showed an upward trend year by year; After the implementation of the second phase (Model 5), the PM2.5 emission damage only increased significantly in 2008 , and then showed a downward trend (the dynamic effect regression coefficient decreased year by year after 2008, but not significant); After the implementation of the third phase (Model 6), from 2013 to 2017, PM2.5 emission damage continued to decrease year by year, and both were significant at the $5 \%$ confidence level. In addition, from the regression coefficient of the dynamic effect in the third stage, it can be found that the 
absolute value of the coefficient is increasing year by year, and the degree of significance also shows an upward trend. This shows that EU ETS has gradually played a role in reducing PM2.5 damage in the third stage, and it is more and more conducive to the reduction of PM2.5 damage.

Table 5. Regression analysis results of dynamic effects

\begin{tabular}{|c|c|c|c|}
\hline & Phase 1 & Phase 2 & Phase 3 \\
\hline Model 4 & Model 5 & Model 6 & \\
\hline $0.07 \star \star$ & $0.06^{*}$ & $-0.05^{\star}$ & \\
\hline$(2.48)$ & $(1.88)$ & $(-1.80)$ & \\
\hline $0.08^{\star \star *}$ & 0.05 & $-0.06^{\star}$ & \\
\hline$(2.46)$ & $(1.47)$ & $(-1.95)$ & \\
\hline $0.11^{\star \star *}$ & -0.003 & $-0.08 * *$ & \\
\hline \multirow[t]{5}{*}{ (2.36) } & $(-0.08)$ & $(-2.00)$ & \\
\hline & -0.05 & $-0.11^{\star \star}$ & \\
\hline & $(-1.21)$ & $(-2.43)$ & \\
\hline & $-0.10 \star \star \star$ & $-0.10 * *$ & \\
\hline & $(-2.22)$ & $(-2.02)$ & \\
\hline Control variables & YES & YES & YES \\
\hline$N$ & 371 & 352 & 395 \\
\hline 0.916 & 0.894 & 0.772 & \\
\hline
\end{tabular}

From the results of the above-mentioned holistic analysis and dynamic effect analysis, it can be seen that the results of the dynamic analysis further support the conclusion of the holistic analysis. Specifically, the impact of EU ETS on PM2.5 damage did not play its due role in the first stage, and the degree of PM2.5 damage has increased. In the second stage of ETS implementation, it can be seen from the result analysis that this stage is a transitional stage. Although the regression analysis results are not significant, the degree of PM2.5 damage still changes from rising to falling. And in the later stage of the implementation of the second stage, ETS began to exert an inhibitory effect on PM2.5 damage, and it became significant at the end of the second stage. The third stage is the stage when ETS is fully functional. No matter from the point of view of significance and regression coefficient, ETS has played a significant effect on the reduction of PM2.5 damage.

\subsubsection{Impact mechanism analysis: further discussion of the analysis results}


By reviewing the specific system design content and actual implementation of the three stages of EU ETS, combined with previous studies by relevant scholars, we can further explain the above analysis results. Specifically, the first phase of the EU's implementation of ETS is the pilot phase, and the EU's emission limits are also difficult to determine; At the same time, most of the emission allowances allocated by member states to market entities are free (about 95\%), most allowances (especially those in Eastern Europe) cannot enter the market, and the allowance prices is fluctuate (Wng, 2009). At the same time, its initial scope of implementation was limited to large energy-consuming companies and carbon dioxide emissions, and did not expand to more industrial fields, smaller-scale production companies, and other types of greenhouse gases. This may be the main reason why the first phase of ETS did not work (Zang et al., 2020). With the implementation of the second phase, related emission requirements have been further strengthened, more countries and greenhouse gas emissions have also been included in the scope, and the degree of punishment has been increased. As a result, it led to a change in the degree of PM2.5 damage in the second phase. After the accumulation of experience in the first two stages of implementation, the ETS in the third stage has been greatly improved, and the system has gradually matured. Therefore, in the third stage, its effect on PM2.5 emission reduction has been most effectively exerted (Yan et al., 2020).

So what is the possible impact mechanism of ETS on PM2.5 damage reduction? Based on previous studies, this paper believes that the effect of ETS on PM2.5 reduction is mainly through the following two ways. 1. Industrial transfer and industrial structure upgrade approach. EU ETS is an effective marketbased environmental regulation, which will follow the "pollution paradise" hypothesis. That is to say, its implementation will directly affect the industrial transfer of relevant heavy pollution industries, transfer to other countries or regions with lower environmental requirements, or directly cause the shutdown of relevant heavy pollution enterprises (Fan et al. 2017; Xuan \& Qian, 2020). At the same time, related studies have also confirmed that the implementation of EU ETS will promote the upgrading of the industrial structure of EU member states, prompt enterprises to increase green total factor productivity, and thereby reduce polluting gas emissions (Zang et al., 2020; Xian et al., 2018 ; Yang et al., 2013). As mentioned in the introduction and the review section of this paper, carbon reduction, greenhouse gas reduction and PM2.5 reduction have a synergistic effect. Therefore, it is necessary to believe that the transfer of polluting industries and the upgrading of industrial structure will promote the reduction of PM2.5 damage. 2. Green technology innovation approach. Green technological innovation can be said to be the essential factor of ETS affecting PM2.5 emission reduction. Previous research has shown that market-based environmental policy tools have a stronger effect of technological progress (Harrison et al. 2015). Studies from many countries have also proved that environmental regulation will force companies to further optimize resource allocation, improve energy efficiency and productivity by promoting green innovation, to promote productivity growth and technological progress by replacing, updating and upgrading equipment and technologies. For example, studies from the European Union (Jaraite and Maria, 2012), the United States (Rassier and Earnhart 2015) and China (Wang et al. 2016). The latest research by Yan et al. (2020) directly proves that green technology innovation has played a completely intermediary role between ETS and air pollution. 


\section{Conclusions And Policy Implications}

To study and formulate effective environmental regulations to control and reduce the concentration of $\mathrm{PM}_{2.5}$ in the air, especially to clarify the effect of the relevant ETS on the emission reduction of air pollutants is a research topic with important practical significance and theoretical value. Based on the PSM-DID method, this paper selects $\mathrm{PM}_{2.5}$ damage and other related data from 147 countries in the World Development Index (WDI) database. This paper examined whether the EU ETS implementation has a spillover effect on $\mathrm{PM}_{2.5}$ damage reduction, clarified the ETS impact effect at its different implementation stages, and further discussed the related impact mechanisms and approaches. The following research conclusions are obtained:

First, this study found that the degree of PM2.5 damage in countries participating in the EU ETS has changed from an increase in the first phase to a transition in the second phase then to a significant reduction in the third phase. Therefore, the EU ETS has an important spillover effect on the reduction of PM2.5 emission damage in the pilot area. Combined with an in-depth study of the phased implementation of the EU's ETS, it is found that there is only a relatively strict ETS (Such as covering more energy-consuming industries, more air emissions, and stricter emission targets, etc.) can really play a role in reducing PM2.5 emission damage. Otherwise, it will not really effectively reduce PM2.5 emission damage.

Second, in each stage, the EU ETS has a dynamic effect on the reduction of PM2.5 damage. Looking at it separately, with the passage of policy implementation time, the effect of the EU ETS on the reduction of PM2.5 damage has shown a slow increase until it stabilizes. The policy effect also changed from the weak effect in the first stage to the strong effect in the third stage. Therefore, adhere to the pilot work of the ETS and further improve and enrich the connotation and scope of the ETS. It also has important reference value for other countries outside EU, especially for the improvement of air quality in developing countries.

We can also draw some useful policy implications from these conclusions:

Firstly, the research conclusions of this paper are an effective supplement to the previous researches on the environmental effects of ETS, indicating that the implementation of EU ETS can not only be used as an important market-based environmental regulatory tool to improve climate change, but also can effectively reduce the concentration of smog and maximize the efficiency of coordinated governance of air pollution. In other words, effective ETS can realize the coordinated management of $\mathrm{CO} 2$ emissions and PM2.5 emissions in the natural environment. Therefore, other countries can follow the implementation experience of the EU ETS, vigorously promote the exploration and innovation of ETS, and form a unified national carbon market trading system as soon as possible.

Secondly, other policies and investment on reducing energy consumption intensity, carbon emission intensity, smog density, and energy saving technologies, can be designed in conjunction with the ETS system to further expand the effectiveness of collaborative governance. At the same time, it should be 
noted that, in order to avoid possible overlap in management and evaluation between the current energysaving or emission-reduction policies and the emissions trading system, so is necessary to strengthen overall planning and research, and strengthen the management of the connection between emission reduction policies and the ETS.

Finally, the prerequisite for environmental regulation to produce economic or environmental effects is the effective implementation of policy tools. In addition, the effectiveness of the effects of the ETS is also related to differences in economic characteristics such as resource endowments and regional development levels in the pilot areas. The flexible application of the "common but differentiated responsibilities" principle among EU member states can provide a reference for other countries with uneven domestic development to formulate emission reduction policies. At the same time, the government should focus on improving the supporting policies and infrastructure for the operation of the emissions trading market system to fully activate the emissions trading market and give full play to the governance effects of the policies.

This research still has certain shortcomings. This paper examines the EU ETS policy and its effects from the national level, however, compared with the country as the main body of PM2.5 emissions, various industries, especially different types of enterprises, and even different types of lifestyles, should be directly studied and analyzed, we believe that the conclusion of the analysis will be more objective and universal. In addition, although this paper discusses the possible ways that ETS affects PM2.5 emission reduction, due to space and data, this paper does not construct an analysis model for further testing. When the data is available in the follow-up research, the relevant discussions of this research can be further explored in order to obtain stronger evidence.

\section{Declarations}

\section{Ethical Approval}

Not applicable

\section{Consent to Participate}

Not applicable

\section{Consent to Publish}

Not applicable

\section{Authors Contributions}

Liang Wan: Conceptualization, Formal analysis and Writing-original draft;

Shanyong Wang: Methodology, Writing- review \& editing; 
Jianing Zang: Writing- review \& editing, Data curation;

Qiaoqiao Zheng: Writing- review \& editing, Data curation;

Wenpei Fang: Writing- review \& editing, Data curation.

\section{Funding}

This work was supported by the Humanities and Social Science Research Project of the Ministry of Education of China (20YJC630138), the Anhui Natural Science Foundation (2008085QG345), the Fundamental Research Funding for Central Universities of China (WK2040000023), the New Liberal Arts Fund of University of Science and Technology of China (YD2040002010) and the National Natural Science Foundation of China (Grant number 71974177).

\section{Competing Interests}

The authors declare that they have no conflict of interest.

\section{Availability of data and materials}

The datasets used and/or analyzed during the current study are available from the corresponding author on reasonable request.

\section{References}

Abrell, J., Anta, N.F., Georg, Z., 2011. Assessing the impact of the EU ETS using firm level data. Bruegel Working Paper, 2011/08, Bruegel, Belgium.

Allan, G., Lecca, P., McGregor, P., et al., 2014. The economic and environmental impact of a carbon tax for Scotland: a computable general equilibrium analysis. Ecol. Econ. 100: 40-50.

Anger, N., Oberndorfer, U., 2008. Firm performance and employment in the EU emissions trading scheme: An empirical assessment for Germany. Energy Policy, 36(1), 12-22.

Apergis, N., 2016. Environmental Kuznets curves: new evidence on both panel and country-level CO2 emissions. Energy Econ. 54, 263-271.

Caliendo, M., Kopeinig, S., 2008. Some practical guidance for the implementation of propensity score matching. Journal of economic surveys, 22(1), 31-72.

Cerin, P., 2006. Bringing economic opportunity into line with environmental influence: A discussion on the Coase theorem and the Porter and van der Linde hypothesis. Ecological Economics, 56(2), 209-225.

Chen, X., Qian, W.W., 2020. Effect of marine environmental regulation on the industrial structure adjustment of manufacturing industry: An empirical analysis of China's eleven coastal provinces. Marine 
Policy, 113:103797.

Cheng, Z.H., Li, L.S., Liu, J., 2017. The emissions reduction effect and technical progress effect of environmental regulation policy tools. Journal of Cleaner Production, 149(15), 191-205.

China Meteorological Administration, 2013. Reducing greenhouse gas emissions can help reduce premature deaths. Available from:

http://www.cma.gov.cn/2011xwzx/2011xqhbh/2011xdtxx/201309/t20130924_227023.html. Accessed 31 December 2020.

Cui, L.B., Ying, F., Lei, Z., Bi, Q.H., 2014. How will the emissions trading scheme save cost for achieving China's 2020 carbon intensity reduction target. Applied Energy, 136(12), 1043-1052.

Dong Feng, Yu Bolin, Pan Yuling, 2019. Examining the synergistic effect of CO2 emissions on PM2.5 emissions reduction: Evidence from China. Journal of Cleaner Production, 223:759-771.

Dong, F., Wang, Y., Su, B., et al., 2019b. The process of peak CO2 emissions in developed economies: a perspective of industrialization and urbanization. Resour. Conserv. Recycl. 141:61-75.

EU, 2020. EU Emissions Trading System. Available from: https://ec.europa.eu/clima/policies/ets_en. Accessed 31 December 2020.

European Environment Agency, 2016. Available from: http://www.199it.com/archives/542273.html. Accessed 30 December 2020.

Evidence based on a “Quasi-Natural Experiment”. Industrial Economic Research, 88(3): 69-80.

Fan, D., Wang, G.W., Liang, P.F., 2017. Analysis of the performance of carbon emissions trading right in China:The evaluation based on the difference-in-difference model. China Environmental Science, 37(6): 2383-2392.

Groosman, B., Muller, N.Z., O’Neill-Toy, E., 2011. The ancillary benefits from climate policy in the United States. Environ. Resour. Econ. 50: 585-603.

Haines, A., McMichael, A.J., Smith, K.R., et al., 2009. Public health benefits of strategies to reduce greenhouse-gas emissions: overview and implications for policy makers. Lancet. 374: 2104-2114.

Hoffmann, V.H., 2007. EU ETS and investment decisions: The case of the German electricity industry. European Management Journal, 25(6), 464-474.

Hübler, M., Sebastian, V., Andreas, L., 2014. Designing an emissions trading scheme for China: An up-todate climate policy assessment. Energy Policy, 75(6), 57-72.

Kara, M., Syri, S., Lehtilä, A., Helynen, S., Kekkonen, V., Ruska, M., Forsström, J., 2008. The impacts of EU $\mathrm{CO} 2$ emissions trading on electricity markets and electricity consumers in Finland. Energy Economics, 
30(2), 193-211.

Laing, T., Sato, M., Grubb, M., Comberti, C., 2014. The effects and side-effects of the EU emissions trading scheme. Wiley Interdisciplinary Reviews: Climate Change, 5(4), 509-519.

Li, G., Zhang, W., 2017. Research on industrial carbon emissions and emissions reduction mechanism in China's ETS. China Popul. Resour. Environ. 27 (10): 141-148.

Li, H., Zhang, M., Li, C., et al., 2019. Study on the spatial correlation structure and synergistic governance development of the haze emission in China. Environ. Sci.Pollut. Control Ser. 26 (12):12136-12149.

Li, K., Lin, B.Q., 2015. Impacts of urbanization and industrialization on energy consumption/CO2 emissions: does the level of development matter? Renew. Sustain. Energy Rev. 52, 1107-1122.

Li, W., Jia, Z.J., 2016. The impact of emission trading scheme and the ratio of free quota: A dynamic recursive CGE model in China. Applied Energy, 174, 1-14.

Liu, J., Li,Y., Bai, X.Y., et al., 2020. Environmental regulations, spatial spillover effects, and urban environmental quality: Evidence from Guanzhong area in China. Journal of Catastrophology. 35 (4) :1-7.

Lv, S.J., Shen, X.C., Zhang, X.M., 2015. Environmental regulations: An analysis based on environmental regulation theory. Journal of SJYU (Philosophy and Social Sciences). 23(6):50-59.

Muûls, M., Colmer, J., Martin, R., Wagner, U.J., 2016. Evaluating the EU Emissions Trading System: Take it or leave it? An assessment of the data after ten years. Briefing paper, 1-12.

Nemet, G.F., Holloway, T., Meier, P., 2010. Implications of incorporating air-quality co-benefits into climate change policymaking. Environ. Res. Lett. 5: 014007.

Parliament of Australia, 2013. Emissions trading schemes around the world.

Porter, M., 1996. America's green strategy. Business and the environment: A reader, 33.

Porter, M.E., Van der Linde, C., 1995. Toward a new conception of the environment-competitiveness relationship. Journal of Economic Perspectives, 9(4), 97-118.

Sancho, F., 2010. Double dividend effectiveness of energy tax policies and the elasticity of substitution: a CGE appraisal. Energy Policy. 38: 2927-2933.

Shao, S., Li, X., Cao, J., Yang, L., 2016. China's economic policy choices for governing smog pollution based on spatial spillover effects. Econ. Res. J. 9:73-88.

Smale, R., Hartley, M., Hepburn, C., Ward, J., Grubb, M., 2006. The impact of $\mathrm{CO} 2$ emissions trading on firm profits and market prices. Climate Policy, 6(1), 31-48. 
Stuart, E.A. et al., 2014. Using propensity scores in difference-in-differences models to estimate the effects of a policy change. Health Serv Outcomes Res Methodol, 14(4): 166-182.

Sun, R., Dan, K., Chang, D., 2014. The influences of carbon trading on energy, economy and environment and a legitimate range calculation of carbon pricing. China Population, Resources and Environment, 24(7), 82-90.

United Nations Environment Programme, 2012. Global environment outlook 5. 5:1-20.

Van Leeuwen, G., Mohnen, P., 2017. Revisiting the Porter hypothesis: an empirical analysis of green innovation for the Netherlands. Economics of Innovation and New Technology, 26(1-2), 63-77.

Vennemo, H., Aunan, K., Jianwu, H., Tao, H., Shantong, L., 2009. Benefits and costs to China of three different climate treaties. Resour. Energy Econ. 31: 139-160.

Wang, L.X., 2012. Implementation of the EU ETS and an economic analysis. World Chinese Entrepreneur Economic Yearbook (Theoretical Edition), 5-6.

Wng, W.N., 2009. Some analyses on the EU emissions trading scheme and its effecsts. World Econ Stud, 7:68-73.

Xian, Y., Wang, K., Shi, X., Zhang, C., Wei, Y.M., Huang, Z., 2018. Carbon emissions intensity reduction target for China's power industry: an efficiency and productivity perspective. J. Clean. Prod. 197, 10221034.

Xu, B., Lin, B., 2016. Regional differences of pollution emissions in China: contributing factors and mitigation strategies. J. Clean. Prod. 112:1454-1463.

Xu, W., Sun J., Liu, Y., et al., 2019. Spatiotemporal variation and socioeconomic drivers of air pollution in China during 2005-2016. Journal of Environmental Management, 245: 66-75.

$\mathrm{Xu}, \mathrm{Y}$., Masui, T., 2009. Local air pollutant emission reduction and ancillary carbon benefits of SO2 control policies: application of AIM/CGE model to China. Eur. J. Oper. Res. 198: 315-325.

Xue, B., Ma, Z., Geng, Y.,et al., 2015. A life cycle co-benefits assessment of wind power in China. Renew. Sustain. Energy Rev. 41:338-346.

Yan, Y.X., et al., 2020. Emissions trading system (ETS) implementation and its collaborative governance effects on air pollution: The China story. Energy Policy. 138: 111282.

Yang, X., Teng, F., Wang, G., 2013. Incorporating environmental co-benefits into climate policies: a regional study of the cement industry in China. Appl. Energy. 112: 1446-1453.

Yang, Y.Y., Zhao, T., Wang, Y.N., Shi, Z.H., 2015. Research on impacts of population related factors on carbon emissions in Beijing from 1984 to 2012. Environ. Impact. Assess. Rev. 55, 45-53. 
Zang, J., Wan, L., Li, Z., et al., 2020. Does emission trading scheme have spillover effect on industrial structure upgrading? Evidence from the EU based on a PSM-DID approach. Environmental Science and Pollution Research. 27(11):12345-12357.

Zhang Z.Q., 2017. Does environmental regulation improve the urban environmental quality in China?

Zhang, C., Shi, D., Li, P.F., 2017. The potential effects of China's implementation of inter-provincial carbon emissions rights trading. Finance and Trade Economics, 2, 93-108.

Zhang, Y.J., Wei, Y.M., 2010. An overview of current research on EU ETS: Evidence from its operating mechanism and economic effect. Applied Energy, 87(6), 1804-1814.

Zhang, Z., 2015. Carbon emissions trading in China: the evolution from pilots to a nationwide scheme. Clim. Policy. 15 (Suppl. 1): S104-S126.

Zhou, X.H., Fan, Q.Q., 2016. Mechanisms for the attainment of carbon intensity reduction targets and the optimal design of industry emissions abatement processes. The Journal of World Economy, 7, 168-192.

\section{Figures}

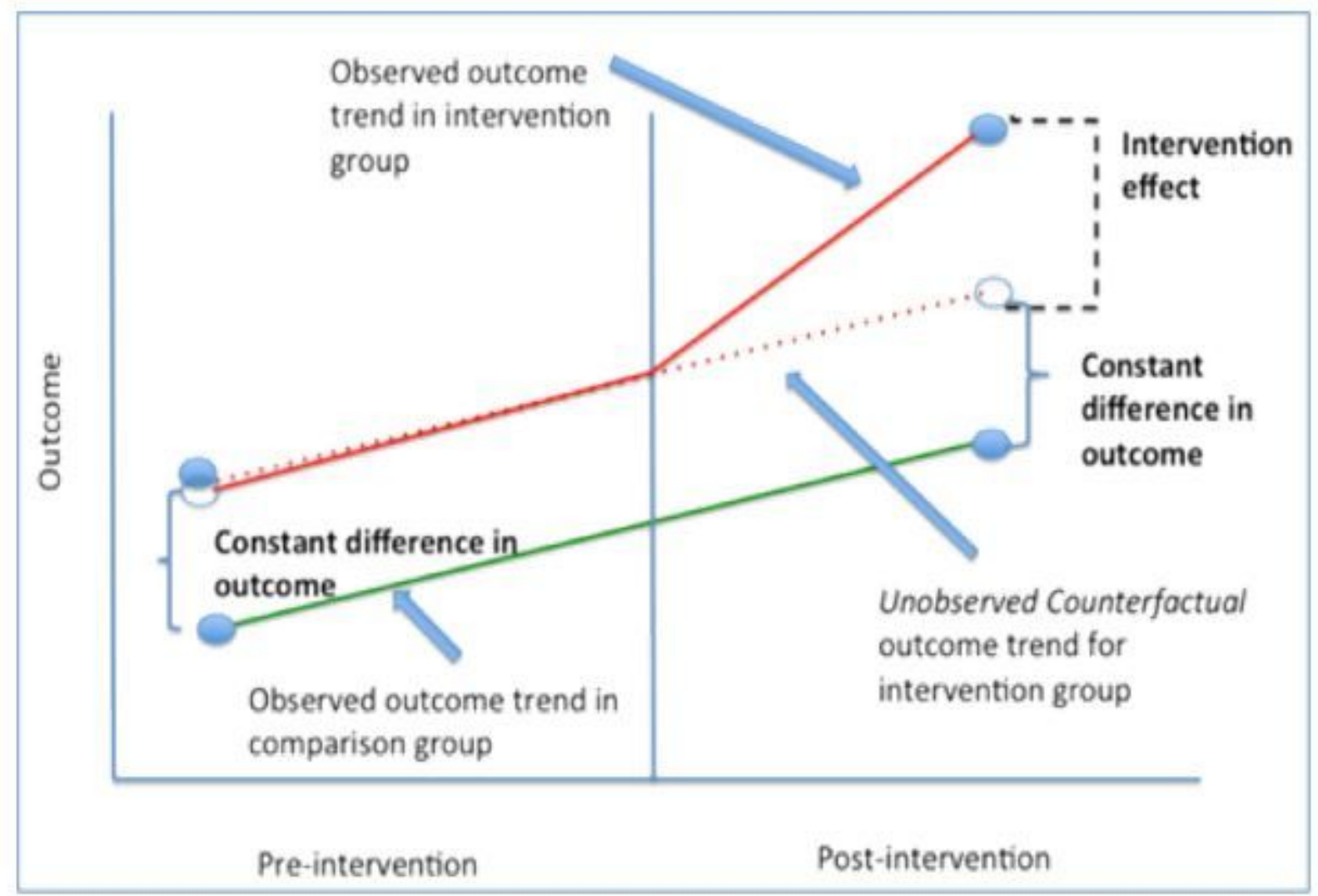

\section{Figure 1}


The estimation principle of DID method

Page 25/25 